\title{
Cancers in concrete workers: results of a cohort study of 33668 workers
}

\author{
Anders Knutsson, Lena Damber, Bengt Järvholm
}

\begin{abstract}
Objectives-To study cancer morbidity patterns in concrete workers.

Methods-A cohort of 33503 concrete workers was enrolled in the study from 1971-86. The average duration of follow up was 19.4 years (582 225 person-years). The workers' cancer morbidity was compared with the morbidity of the general population.

Results-A total of 3572 incident cancers were observed. Significantly increased standardised incidence ratios (SIRs) were found for all malignant neoplasms (SIR 107; $95 \%$ confidence interval $(95 \% \mathrm{CI}) 103$ to 110 ), cancer of the lip (SIR 179; 95\%CI 134 to 234), cancer of the stomach (SIR $139 ; 95 \%$ CI 122 to 158 ), cancer of the lung (SIR 125; 95\%CI 114 to 137), and cancer of the prostate (SIR 108; 95\%CI 101 to 116 ). Reduced risk was found for cancer of the large intestine (SIR 80; 95\%CI 69 to 93) and cancer of the testis (SIR 50; 95\%CI 26 to 87). Smoking was more prevalent among the concrete workers than in the general population $(50 \%$ v $35 \%)$.

Conclusion-The study has shown a slightly increased overall risk of cancer among concrete workers. The increased risk of lung cancer could entirely be due to differences in smoking habits between concrete workers and the general population. There is a possibility that the smoking also has contributed to the increased risks of stomach cancer and lip cancer, but occupational factors may have contributed to these cancer sites.

(Occup Environ Med 2000;57:264-267)
\end{abstract}

Occupational

Medicine, Department of Public Health and

Clinical Medicine, Umeå University,

Umeå, Sweden

A Knutsson

B Järvholm

Department of

Oncology, Umeå

University, Umeå,

Sweden

L Damber

Correspondence to:

Dr A Knutsson,

Occupational Medicine,

Department of Public Health

and Clinical Medicine, Umeå

University Hospital, S-90185

Umeå, Sweden

email anders.knutsson@

envmed.umu.se

Accepted 29 November 1999
Keywords: occupational diseases; constructions workers; smoking

Some epidemiological studies have indicated that cement and concrete dust might be carcinogenic. A case-control study in Denmark found that people working in concrete and cement manufacturing had an increased risk of laryngeal cancer. ${ }^{1}$ A Finnish case-control study indicated that cancer of the urinary bladder was more common in subjects that had been exposed to concrete and cement. ${ }^{2}$ Siemiatychi et $a l^{\beta}$ carried out a case-control study with 3726 subjects in Montreal and found that exposure to concrete dust was associated with nonadenocarcinoma of the lung (odds ratio (OR) 2.5), and Non-Hodgkin's lymphoma (OR 2.9). Jakobsson et al carried out at a cohort study of 2400 men, employed for at least 12 months in two Swedish cement factories, and reported an increased risk of colorectal cancer (standardised incidence ratio (SIR) 1.61), mainly due to an increased risk of tumours in the right part of the colon (SIR 2.73). ${ }^{4}$ In those men who had been employed $>15$ years they also found increased risk of cancer of rectum (SIR 1.47), lung (SIR 1.26), and pancreas (SIR 1.33). The relative risk of cancer of the stomach was 1.1.

These intriguing findings have created a need for longitudinal cohort studies of concrete workers to investigate whether specific cancers are associated with concrete dust. This study is the first cohort study of cancer incidence of concrete workers in the construction industry.

\section{Material and methods}

This is a cohort study in which the incidence of cancer in concrete workers in the construction industry is compared with the incidence in the general Swedish population. The cohort is previously described.

From 1969 to 1992 the Construction Industry's Organisation for Working Environment, Safety and Health provided outpatient medical services to construction workers in Sweden. ${ }^{6}$ Health examinations were offered to all workers in the building industry every second or third year. The health checkups were carried out in stationary or mobile clinics, staffed by nurses and a physician. On average, each cohort member underwent three health examinations. Before each examination, the worker filled out a questionnaire, including a detailed smoking history and questions on previous and current symptoms. The answers were checked by a nurse together with the worker to reduce misunderstandings and incomplete answers. The occupational coding included around 200 job titles. The occupational coding, however, refers only to the job title at the time of the first examination if we do not have a complete lifetime work history. From 1971 data from the health examinations were computerised. A total of 389000 people were included in the registry until 1992. At follow up to the end of 1996, 605 people were unidentified $(0.16 \%)$ and about $2 \%$ had emigrated. In this study we have considered all male concrete workers $(n=33$ 503), who underwent a health checkup during 1971-86. However, most of the the study subjects were included in the early 1970s. From 1971 to $197395 \%$ of those $<50$ years old, and $99 \%$ of those $\geqslant 50$ years old underwent their first examination.

The cohort of concrete workers was linked to the Swedish Cancer Registry and to the Swedish Causes of Death Registry by the national identification number. The Swedish Cancer 
Registry is a national register containing incident cases of cancer occurring in Sweden since 1958. Reporting to the register is mandatory for all malignant tumours. The incidence of all cancers from the time of the first examination to 31 December 1993 were included in the study.

To assess whether the concrete workers had been exposed to silica, the mortality from silicoses was explored through linkage to the National Death Registry.

Questionnaire data from the health examination included questions on smoking habits. In $77 \%$ of the concrete workers it was possible to classify the subject as being a current smoker or not. Data on smoking habits in the adult male general population were obtained from a national survey of a random sample of the Swedish population in 1980-1. The prevalence of current smoking in the cohort of concrete workers examined in 1980-1 were compared with the prevalence of smokers in the genereral population to assess the impact fraction of smoking on lung cancer in concrete workers.

In 24153 concrete workers the health examinations were carried out more than once. Among those, $50 \%$ had remained in the same job at all occasions.

\section{CONCRETE WORK}

Concrete is a mixture of cement, sand, rock, and water. Cement, which is made of chalk and clay, contains different calcium compunds. Mixtures are often added to cement to change concrete setting time and to improve the concrete quality. These mixtures are sometimes carcinogenic-for example, asbestos. Since 1975 the use and exposure to asbestos has decreased drastically through regulations. ${ }^{7}$ Concrete might also contain radioactive granite aggregates, and radon gas might diffuse through concrete. Silica and chromium are other carcinogenic components of concrete. Hexavalent chromate, which has been a contamination of cement, is an established cause of lung cancer. ${ }^{8}$ Due to the risk of chromium eczema, addition of ferric chloride in concrete has been mandatory in Sweden since the beginning of the 1980s.

During recent decades the job tasks have changed among concrete workers in the construction industry. Previously, concrete was mainly made on the construction site, where sand was mixed with cement and water in a motor driven mixer. Today, usually ready mixed concrete is delivered to the work site by lorries with a rotating drum. Probably the exposure to cement and concrete dust has diminished because of this.

Most the concrete workers in the present study experienced their occupational exposure during the 1950s, 1960s, and 1970s. During that time, the job was basically a manual job and included setting the forms for holding the concrete, preparing reinforcing bars, and mixing of concrete. The concrete was then spread with shovels. The freshly poured concrete slab was vibrated, and the surface was levelled off. Concrete workers also stripped the forms.
STATISTICAL METHODS

Each cohort member contributed person-years from the date of the first health examination to the date of a diagnosis of cancer, death, emigration, or 31 December 1993, whichever occurred first. The number of cases and person-years were computed within 5 year age intervals. Expected morbidity was calculated by multiplying the person-years during the observation period with the incidences, stratified for calendar year and age. Standardised incidence ratios (SIRs) were calculated as ratios between observed and expected number of cancers. The two tailed $95 \%$ confidence intervals (95\% CIs) of SIRs, based on the assumption of a Poisson distribution of the observed cases, were calculated with approximate limits. Impact fraction (IF) for smoking is given by:

$$
\mathrm{IF}=((\mathrm{p} 1-\mathrm{p} 2) \times(\mathrm{RR}-1)) /(\mathrm{p} 1 \times(\mathrm{RR}-1)+1)
$$

where $\mathrm{p} 1=$ prevalence of smoking in concrete workers, $\mathrm{p} 2=$ prevalence of smoking in the general population, and $R R=$ relative risk of cancer associated with smoking. For lung cancer we have assumed that the relative risk in general is $10,{ }^{9}$ and for gastric carcinoma $1.6 .{ }^{10}$ The interpretation of the impact fraction is analogous to that of the attributable fraction but the prevalence of exposure in the reference group does not have to be zero but can be any proportion. ${ }^{11}$ Poisson regression was used to model the relative risk of lip cancer relative to smoking habits among the concrete workers.

\section{Results}

The average duration of follow up was 19.4 years. The duration of follow up was similar in the different age groups (table 1). The total number of person-years accumulated was 582225 . There were slightly more cancers than expected; 3572 cancers were recorded compared with 3346.6 expected (SIR 107; $95 \%$ CI 103 to 110 , table 2). Significantly increased SIRs were found for cancer of the lung, gastric carcinoma, cancer of the lip, and cancer of the prostate. During follow up silicosis was observed as the underlying cause of death among nine concrete workers.

Among the concrete workers $47 \%$ were nonsmokers, $12 \%$ pipe smokers, $33 \%$ cigarette smokers, and $9 \%$ combined pipe and cigarette smoking. The cumulative incidence of cancer of the lip in these four groups are presented in table 3. Poisson regression, where the results

Table 1 People (n) at entry and years of follow up in different age groups

\begin{tabular}{lcl}
\hline Age at entry & People (n) & $\begin{array}{l}\text { Cohort follow up }(y) \\
\text { (median, 25th-75th } \\
\text { percentiles) }\end{array}$ \\
\hline $15-29$ & 8451 & $20,15-22$ \\
$30-34$ & 3448 & $21,19-23$ \\
$35-39$ & 3142 & $21,19-23$ \\
$40-44$ & 3122 & $21,19-23$ \\
$45-49$ & 3652 & $21,20-23$ \\
$50-54$ & 4134 & $21,19-22$ \\
$55-59$ & 4041 & $21,18-22$ \\
$60-64$ & 3063 & $21,18-22$ \\
$65-69$ & 442 & $21,18-23$ \\
$70-74$ & 8 & $21,16.5-22.75$ \\
Total & 33503 & $21,18-22$ \\
\hline
\end{tabular}


Table 2 Observed and expected malignancies (1971-92) for all male concrete workers (only cancer codes with more than six observed cases are included in the table)

\begin{tabular}{|c|c|c|c|c|}
\hline Tumour site (ICD-7 code) & Obs & $\operatorname{Exp}$ & SIR & $95 \% C I$ \\
\hline Lip (140) & 53 & 29.6 & 179 & 134 to 234 \\
\hline Tongue (141) & 11 & 12.8 & 86 & 43 to 153 \\
\hline Salivary glands (142) & 8 & 8.5 & 94 & 40 to 185 \\
\hline Oral (144) & 12 & 13.5 & 89 & 46 to 155 \\
\hline Middle pharynx (145) & 9 & 9.8 & 92 & 42 to 175 \\
\hline Lower pharynx (147) & 10 & 10.7 & 63 & 45 to 171 \\
\hline Oesphagus (150) & 46 & 44.5 & 103 & 76 to 138 \\
\hline Stomach (151) & 243 & 174.6 & 139 & 122 to 158 \\
\hline Small intestine (152) & 22 & 19.0 & 116 & 73 to 175 \\
\hline Large intestine, except rectum (153) & 187 & 232.7 & 80 & 69 to 93 \\
\hline Rectum (154) & 167 & 165.5 & 101 & 86 to 117 \\
\hline Liver $(155)$ & 81 & 82.9 & 98 & 78 to 122 \\
\hline Pancreas (157) & 108 & 110.1 & 98 & 80 to 118 \\
\hline Larynx (161) & 45 & 39.7 & 113 & 83 to 152 \\
\hline Trachea, bronchus, and lung (162) & 473 & 378.0 & 125 & 114 to 137 \\
\hline Pleura (1622) & 18 & 10.9 & 165 & 98 to 261 \\
\hline Prostate (177) & 769 & 709.0 & 108 & 101 to 116 \\
\hline Testis (178) & 12 & 24.1 & 50 & 26 to 87 \\
\hline Penis (179) & 13 & 11.5 & 113 & 60 to 193 \\
\hline Kidney (180) & 135 & 142.7 & 95 & 79 to 112 \\
\hline Bladder (181) & 262 & 246.5 & 106 & 94 to 120 \\
\hline Melanoma (190) & 88 & 110.2 & 80 & 64 to 98 \\
\hline Skin, melanoma excluded (191) & 126 & 128.7 & 98 & 82 to 117 \\
\hline Eye (192) & 7 & 9.1 & 77 & 31 to 158 \\
\hline Brain (193) & 113 & 105.6 & 107 & 88 to 129 \\
\hline Thyroid gland (194) & 11 & 18.1 & 61 & 30 to 109 \\
\hline Endocrine system (195) & 49 & 42.6 & 115 & 85 to 152 \\
\hline Bone (196) & 10 & 6.2 & 161 & 77 to 296 \\
\hline Soft tissue (197) & 26 & 24.5 & 106 & 69 to 155 \\
\hline Non-Hodgkin's lymphoma (200) & 121 & 107.6 & 112 & 93 to 134 \\
\hline Hodgkin's lymphoma (201) & 21 & 19.6 & 107 & 66 to 163 \\
\hline Multiple myeloma (203) & 55 & 52.5 & 105 & 79 to 136 \\
\hline Leukaemia and polycythemia vera (204) & 105 & 101.1 & 104 & 85 to 126 \\
\hline All sites & 3572 & 3346.6 & 107 & 103 to 110 \\
\hline
\end{tabular}

Table 3 Relative risk of lip cancer among concrete workers in different smoking groups

\begin{tabular}{lll}
\hline Smoking category & Cases $(n) * \begin{array}{l}\text { Relative risk } \\
(95 \% \text { CI }) t\end{array}$ \\
\hline Non-smokers & 17 & 1.00 \\
Cigarette smokers & 11 & $1.50(0.35$ to 0.49$)$ \\
Pipe smokers & 15 & $2.03(0.45$ to 9.17$)$ \\
Pipe and cigarette smokers & 2 & $3.93(0.90$ to 17.24$)$
\end{tabular}

* Missing values on smoking for eight cases.

tRR $(95 \% \mathrm{CI})$ adjusted for age through Poisson regression.

were adjusted for age, yielded an increased risk of cancer of the lip among smokers, expecially in pipe smokers.

Smoking was more prevalent among the concrete workers than in the general population in $1981(50 \% v 35 \%)$. Based on the prevalence of smoking the impact fraction of smoking for lung cancer in concrete workers was $30 \%$, and for stomach cancer $7 \%$-that is, smoking accounts for a $30 \%$ excess risk of lung cancer and $7 \%$ excess risk of stomach cancer among the concrete workers.

No clear age trend was found for lung cancer. For stomach cancer an increased risk was found in the highest age groups (figure).

\section{Discussion}

This study has shown that concrete workers had significantly increased relative risks for the following malignancies: lip, stomach, lung, and prostate. Fewer cancers than expected were found in the large intestine and testes. There were 18 cases of pleural mesothelioma among the concrete workers versus 10.9 expected (SIR 165, 95\% CI 98 to 261), indicating that the concrete workers may have had some exposure to asbestos. The moderate risk of mesothelioma indicates a lower exposure to

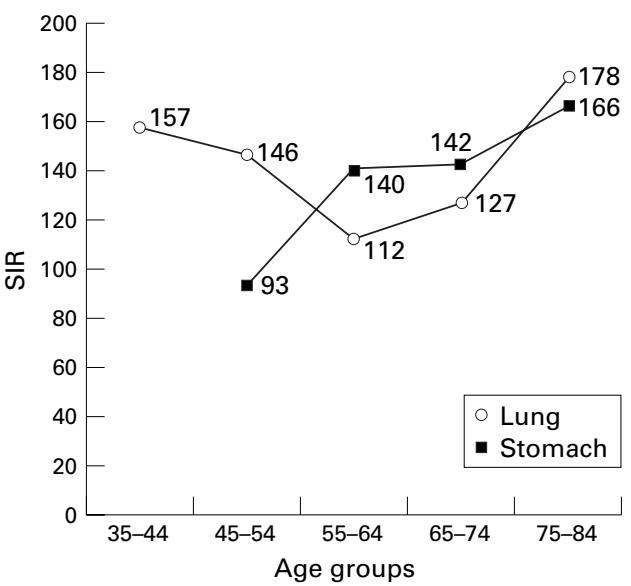

SIRs of lung cancer and stomach cancer among concrete workers relative to age.

asbestos among concrete workers than among, for example, shipyard workers and other groups highly exposed to asbestos. ${ }^{12}$

LUNG CANCER

The increased risk of lung cancer among the concrete workers compared with the incidence in the general population can be explained by the difference in smoking habits, as indicated by the impact fraction.

\section{STOMACH CANCER}

The smoking behaviour could explain only part of the increased risk of stomach cancer among the concrete workers, as the impact fraction was $7 \%$. Furthermore the risk of stomach cancer according to age indicated that the increased risk was highest among the older ages (figure). This finding could be explained by a cohort effect. Concrete workers could previously have been exposed to carcinogens, which have disappeared or diminished during recent decades. It is also possible that changes in food habits could explain why older concrete workers had an increased risk of stomach cancer. An association between exposure to concrete dust and stomach cancer therefore seems less probable.

\section{LIP CANCER}

The increased risk of lip cancer among concrete workers could be due to carcinogenic components in cement or concrete dust but there are other possible causes. Outdoor work is associated with an increased risk of lip cancer. ${ }^{13}$ Many concrete workers are doing mainly outdoor work, and are therefore exposed to sunlight, which is associated with lip cancer. However, if skin cancer is used as a surrogate for exposure to ultraviolet (UV) light, there is no indication in our data that the concrete workers have been more exposed to UV light, as the SIRs for melanoma and skin cancer were not increased. Lip cancer is also associated with lower social class. ${ }^{13}$ Thus, low socioeconomic status could also have contributed to the increased risk of lip cancer. Another possibility is that smoking behaviour has increased the risk of lip cancer. A considerable proportion of the concrete workers were pipe 
smokers, and pipe smokers had a doubled risk for lip cancer compared with non-smokers in this dataset. As there were more smokers among the concrete workers, differences in smoking habits may be one cause of the increased incidence of lip cancer among the concrete workers.

OTHER SITES

Our study did not confirm the findings reported by Siematychi $e t a l^{\beta}$ on the relation between exposure to concrete dust and nonHodgkin's lymphoma.

The low risk for cancer of the large intestine is probably due to the fact that concrete work includes a lot of moving and walking. Previous studies have shown that high physical activity is protective against cancer in the large intestine. ${ }^{14} 15$

Cancer of the testis was lower than in the general population. The aetiology of testicular cancer is to a large extent unknown, but it has been shown that white collar workers generally are at higher risk than blue collar workers. ${ }^{16}$

Use of alcohol probably was not a confounding variable in this study as the SIRs for cancers related to alcohol intake (liver and oesophagus) were not increased.

ASPECTS OF VALIDITY

One of the main weaknesses of our study is the limited information on work history. The job title refers to the status at the time of the examination, and we do not know for how long these workers actually have been concrete workers.

If people with a short history as concrete workers have been included, a risk depending on cumulative dose may be undetected. The loss to follow up is too small to introduce any considerable bias. The Cancer Register is national and only people who emigrate will be lost to follow up. We have not studied the number of emigrants in this cohort, but the emigration in the total cohort of construction workers $(n=389000)$ is very low (about $2 \%$ ).
Thus, the loss to follow up due to emigration seems to be of minor importance.

\section{Conclusions}

Our study has shown a slightly increased overall risk of cancer among concrete workers. The excess risk of lung cancer is probably due to smoking behavioiur. There is a possibility that the smoking also has contributed to the increased risks of stomach cancer and lip cancer. Expoure to UV light due to outdoor work could also have been responsible for the increased risk of lip cancer.

1 Olsen J, Sabroe S. Occupational causes of laryngeal cancer. f Epidemiol Community Health 1984;23:117-21.

2 Tola S, Tenho M, Korkala M-L, et al. Cancer of the urinary bladder in Finland: association with occupation. Int Arch Occup Environ Health 1989;46:43-51.

3 Siemiatycki J, Richardson L, Gérin M, et al. Associations between several sites of cancer and nine organic dusts: results from an hypothesis-generating case-control study in Montreal, 1979-83. Am F Epidemiol 1986;123:235-49.

4 Jakobsson K, Horstmann V, Welinder H. Mortality and cancer morbidity among cement workers. Br F Ind Med 1993; 50:264-72.

5 Nyrén O, Bergström R, Nyström L, et al. Smoking and colorectal cancer: a 20-year follow-up study of Swedish colorectal cancer: a 20-year follow-up study of Swedish

6 Ostlund E, Englund A. Occupational safety and health in the Swedish construction industry. Work Environment the Swedish constructi

7 Järvholm B, Englund A, Albin M. Pleural mesothelioma in Sweden: an analysis of the incidence according to the use of asbestos. Occup Environ Med 1999;56:110-13.

8 Steenland K, Loomis D, Shy C, et al. Review of occupational lung cancer. Am f Ind Med 1996;29:474-90.

9 Wyngaarden JB, Smith LH, eds. Cecil textbook of medicine. Philadelphia: WB Saunders, 1988:38.

10 Tredaniel J, Boffetta P, Buiatti E, et al. Tobacco smoking and gastric cancer: review and meta-analysis. Int $\mathcal{F}$ Cancer 1997; 72:565-73.

11 Rothman KJ, Greenland S, eds. Modern epidemiology. Philadelphia: Lippincott Raven, 1998.

12 Sandén A, Järvholm B, Larsson S, et al. The risk of lung cancer and mesothelioma after cessation of asbestos exposure: a prospective cohort study of shipyard workers. exposure: a prospective cohort

13 Pukkala E, Soderholm AL, Lindqvist C. Cancers of the lip and oropharynx in different social and occupational groups in Finland. Eur f Cancer B Oral Oncol 1994;30:209-15.

14 Garabrant DH, Peters JM, Mack TM, et al. Job activity and colon cancer risk. Am F Epidemiol 1984;119:1005-14.

15 Fredriksson M, Bengtsson, Hardell L, et al. Colon cancer, physical activity, and occupational exposures. A casecontrol study. Cancer 1989;63:1838-42.

16 Van den Eeden SK, Weiss NS, Strader $\mathrm{CH}$, et al. Occupation and the occurrence of testicular cancer. $\mathrm{Am} \mathcal{F}$ Ind Med 1991;19:327-37. 